\title{
A Note from the Editor-in-Chief of Paragone: Past and Present-AJournal on Contestations in the Arts
}

The present issue of this journal is dedicated to the memory of a fine scholar and colleague, Sarah Jordan Lippert (1975-2019), who was an Associate Professor of Art History at the University of Michigan-Flint, USA. She was founder and Senior Editor of the graduate journal Paragone Past and Present: Emerging Scholars, published by the Society for Paragone Studies in collaboration with the Flint Institute of Arts. This new journal, Paragone: Past and Present, a Journal on Contestations in the Arts - with a new editor-in-chief and editorial board, published by Brill, and sponsored by the Association of Textual Scholarship in Art History - is an innovative academic and professional journal. It features scholarship on the history of contestations and confrontations between the arts from antiquity to the present. Contestation is interpreted in the broadest terms from all global contexts. The journal invites articles that take up such questions with regard to any period of Western cultural development but also welcomes discussions of the formation and interaction of media in non-Western cultures. The journal also wishes to advance discussion of a further key phenomenon typical of sixteenth-century culture: the mixing of text and image within particular visual fields, as in the proliferation of emblems of various kinds, as well as in book design or architecture. Such practices resonate with the advertising techniques and formats developed in the modern era, or indeed in contemporary webpage design, with obvious implications especially for the broadcast media. These technical advances are not neutral, however, and so we hope to elicit discussion of the extent to which change in the media landscape accommodates or fosters certain ideological positions.

The authors of this issue are grateful for the visual assistance from and collaborations with private and public collections, galleries, museums, municipal and university libraries, and private collectors, as well as commercial and nonprofit visual resources who have made possible the publication of our illustrations and archival data. The authors also express special gratitude to the Brill Editorial Board and Staff.

\author{
Liana De Girolami Cheney \\ University of Massachusetts Lowell, MA, USA; \\ President, Association for Textual Scholarship in Art History (ATSAH)
}

